\title{
ACRL in Nashville: $A$ focus on dialogue
}

\author{
By Jerilyn Veldof
}

\section{Attend ACRL's 8th National Conference, April 11-14, 1997}

(O) ne of the most critical questions academic librarians have been asking is how we will carve out a unique and critical contribution to the future of information. Will we prosper or will we fade into mediocrity, losing our budgets and our roles on campus? Choosing our futures is pivotal to our survival in the information profession. The ALA Annual Conference in Chicago gave the planning committees for ACRL's 8th National Conference an opportunity to envision key opportunities to discuss our futures with our colleagues across the country - before, during, and after the conference. In order to do this the focus of the Nashville ' 97 conference will be on dialogue and discussion, participation and empowerment. To enact this vision, conference planners from libraries all over the country have been working to rethink the idea of a conference and to create something original and interactive. The new format promises to capture your imagination and inspire you to bring your libraries successfully into the next century.

The crux of the dialogue will occur on the last day of the conference when the thousands of participants will gather to discuss, share, and debate the critical issues arising from the commissioned and contributed papers and panels. Organizers have discussed the possibility of creating a special issue of CGRL that would emerge from this meeting, enabling a much wider audience to learn from this discussion.

To set the scene for this issue, ACRL in Nashville will be an excellent opportunity to en- gage with your colleagues in a dynamic dialogue based on three days of conferencing. In order to keep the conference as cutting edge as possible, abstracts will be accepted in lieu of papers, allowing the newest information and experiences to be shared. Many more presenters from outside librarianship will be solicited, including those invited to deliver forward-thinking papers.

Organizers may release invited papers on the World Wide Web before the conference to prime participants for what's to come. This site will also be available for distribution of handouts from various sessions. Other possibilities include setting up a highly interactive, real-time computer comment board so that participants can comment on and discuss programs as they occur.

The themes for this conference are dynamic and full of possibilities. The central theme, "Choosing Our Futures," indicates an assertive role for academic libraries. Subthemes inspire us to develop this theme further: Partnersbips and competition: will we develop partnerships, be challenged by competition? Changing work, roles, and organization: how will downsizing, technology, budgets, and flattened organizations affect us? Funding: will we let a financial squeeze affect services and collections? Leaming: how will we adapt to new learning technologies and a focus on learning rather than teaching?

Keep your eye on our Web site and watch for updates, papers, and future interactive opportunities, as well as more information about Nashville (http://library.tufts.edu/www/ mcdonald/acrlhome.html). We are at a critical crossroads in academic libraries. Help position us and get involved in Nashville '97. 


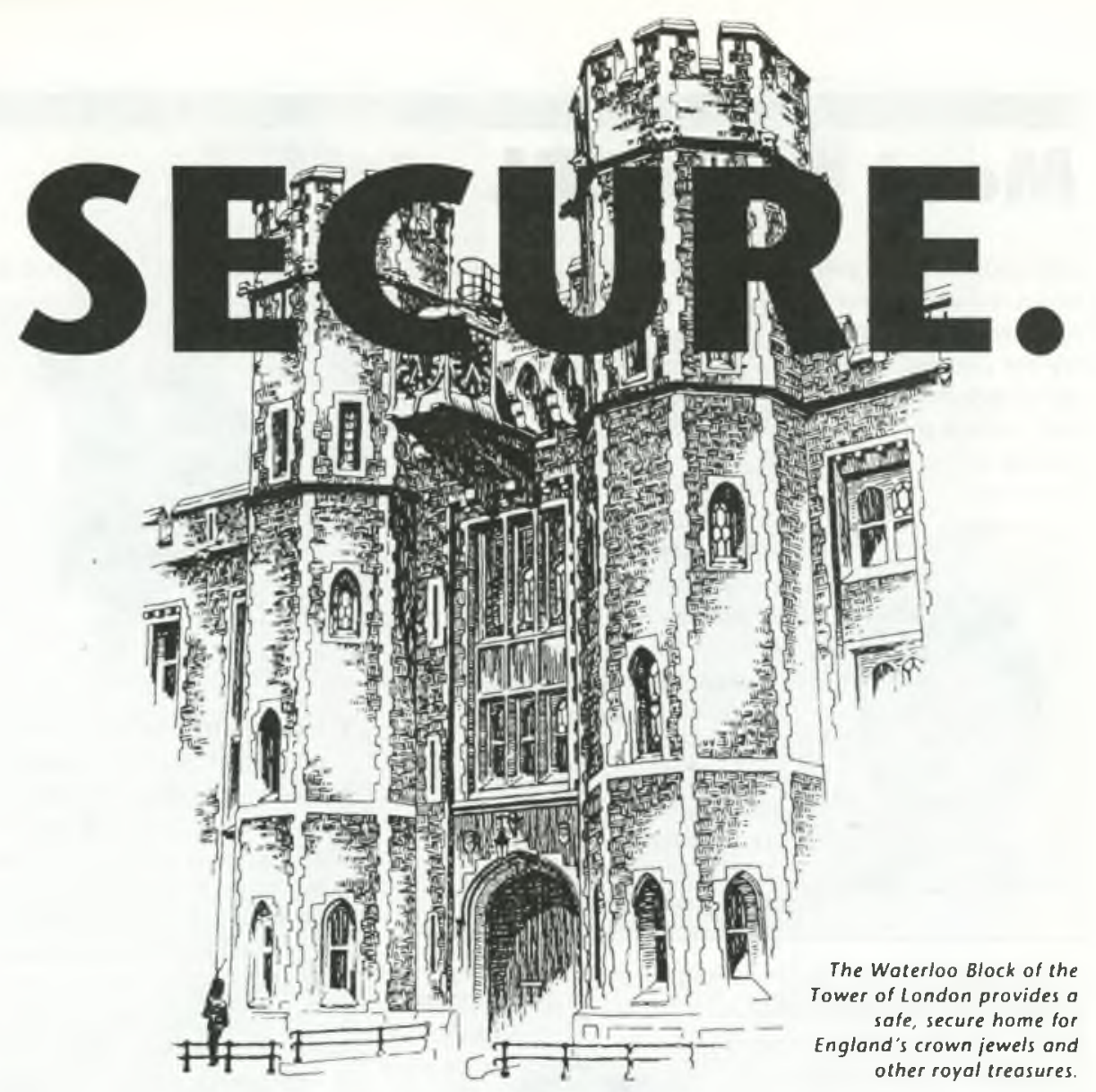

When you order through EBSCO, you can be sure the investment you make in your serials collection is safe. Your assurance against loss to the integrity of your collection includes:

- Unsurpassed fulfillment on journal issues made possible by our global network of publisher contacts and customer service representatives in 19 countries

- Electronic order entry with publishers for the elimination of manual data input errors

- Payment verification sent to publishers with first claims

to reduce the need for additional claims

- Free replacement issues from our Missing Copy Bank ${ }^{\circledR}$ stocked with more than 40,000 issues

- A financially strong and stable organization (Dun \& Bradstreet gives EBSCO Industries Inc. the highest financial strength rating in the industry).

Considering the investment your library makes in its serials collection, it doesn't make sense to trust it to anyone else.

Contact us today: (205) 991-6600 • Fax (205) 995-1636

EBSCO

London Office:

2 kilometers 